UDC 615.011

LBC 52.66

\title{
BETA-GLUCURONIDASE SYSTEM, INTESTINAL MICROFLORA, AND GENESIS OF COLORECTAL TUMORS
}

\author{
Ahmed H. Al-Hemiri \\ Volgograd State University, Volgograd, Russian Federation \\ Moaed O. Aigazally \\ University of Al-Ameed, Karbala, Iraq \\ Valery V. Novochadov \\ Volgograd State University, Volgograd, Russian Federation \\ Anastasia A. Korchagina \\ Volgograd State University, Volgograd, Russian Federation
}

\begin{abstract}
The review analyzes cellular and molecular aspects of the participation of intestinal microflora and related features of luminal metabolism in the occurrence and subsequent development of colon tumors, primarily colorectal cancer. The article describes the problems of increasing frequency of this disease in recent years, the participation of genetic factors in high risk of colorectal cancer progression. According to the authors, microbial associations and the consequences of the interaction between individual types of microorganisms are of importance. The role of the intestinal microflora can largely be reduced to the activity of its enzyme secretion, which changes the ratio of key metabolites in the intestinal lumen and its permeability. These alterations affect the rate of metabolism and renewal of epithelial cells. From these positions, the structural features and biochemical characteristics of betaglucuronidase, as a key enzyme involved in the carcinogenesis of colorectal cancer, are considered in detail. $\&$ The main information about the role of beta-glucuronidase in the clearance of xenobiotics, physiological and pathological consequences of the activity of this enzyme in the intestinal lumen are given. Modern methods for determining the activity, isolation, and purification of beta-glucuronidase, including chromogenic substrate application, are briefly described. At the end of the review, the authors present several approaches based on the use of beta-glucuronidase for targeted delivery of therapeutic agents to the tumor, as an element of complex chemotherapy for colorectal cancer.

Key words: beta-glucuronidase, intestinal microflora, Escherichia coli, colon, colorectal cancer, oncogenesis.

०ै УДК 615.011

ББК 52.66

\section{СИСТЕМА БЕТА-ГЛЮКУРОНИДАЗЫ, КИШЕЧНАЯ МИКРОФЛОРА} И РАЗВИТИЕ ОПУХОЛЕЙ ТОЛСТОЙ КИШКИ
\end{abstract}

\author{
Ахмед Хамид Хумаири \\ Волгоградский государственный университет, г. Волгоград, Российская Федерация \\ Мояд Омран Аль-Газали \\ Университет Аль-Амида, г. Карбала, Ирак \\ Валерий Валерьевич Новочадов \\ Волгоградский государственный университет, г. Волгоград, Российская Федерация
}




\title{
Анастасия Александровна Корчагина
}

\author{
Волгоградский государственный университет, г. Волгоград, Российская Федерация
}

\begin{abstract}
Аннотация. Настоящий обзор посвящен вопросам участия кишечной микрофлоры и связанных с еe жизнедеятельностью особенностей люминального метаболизма в возникновении и последующем развитии опухолей толстой кишки, прежде всего колоректального рака. В работе проанализированы проблемы повышения частоты этого заболевания в последнее время, участие генетических факторов в формировании высокого риска прогрессирования опухолей толстой кишки. Отдельное значение, по мнению авторов, имеют микробные ассоциации и последствия взаимодействия между отдельными видами микроорганизмов. Роль кишечной микрофлоры во многом может быть сведена к активности секретируемых ей ферментов, изменяющих соотношение ключевых метаболитов в просвете кишки и ее проницаемость, что отражается на скорости метаболизма и обновлении клеток эпителия. С этих позиций детально рассмотрены особенности строения и биохимические характеристики бета-глюкуронидазы, как ключевого фермента, участвующего в канцерогенезе рассматриваемой локализации. Приведены основные сведения о роли бета-глюкуронидазы в клиренсе ксенобиотиков, физиологические и патологические последствия активности этого фермента в просвете толстой кишки. Кратко описаны современные методы определения активности, выделения и очистки бетаглюкуронидазы, в том числе с использованием хромогенных субстратов. В конце обзора авторы приводят ряд подходов, основанных на использовании бета-глюкуронидазы, для адресной системы доставки терапевтических средств к опухоли, как элемента комплексной химиотерапии колоректального рака.
\end{abstract}

Ключевые слова: бета-глюкуронидаза, кишечная микрофлора, Esherihia coli, толстая кишка, колоректальный рак, канцерогенез.

\section{Введение}

Рак толстой кишки (колоректальный рак, колоректальная карцинома, CRC) является одной из наиболее распространенных злокачественных опухолей человека с тенденцией к возрастанию числа заболеваний и смертельных случаев во многих странах мира. Показатели заболеваемости у мужчин выше, чем у женщин с примерной 1,4-кратной и 1,5-кратной разницей по заболеваемости (23,6 против 16,3 случая на 100000 человек в год) и смертности (10,8 против 7,2 случаев смерти на 100000 человек в год) соответственно. Данные показатели связаны с тем, что мужчины являются подверженными влиянию окружающих факторов больше, чем генетическим, по сравнению с женщинами, при этом наследственность CRC для женщин составляет $45 \%$, а для мужчин $-28 \%[9 ; 10]$.

Риск развития CRC увеличивается после 50 лет, при этом 90 \% случаев заболевания регистрируются именно у лиц старше этого возраста. Помимо возраста, основными факторами риска возникновения CRC являются наличие случаев заболевания в семье, ожирение, сахарный диабет, малоподвижный образ жизни, курение, высокое потребление алкоголя, принятие пищи с высоким содержанием жиров и низким содержанием клетчатки.
Более 75-95 \% случаев рака толстой кишки встречаются у пациентов с незначительными или отсутствующими генетическими отклонениями [33; 35].

Люди с воспалительным заболеванием кишечника, таким как язвенный колит и болезнь Крона, подвержены высокому риску $\mathrm{CRC}$, который тем выше, чем больше длительность воспалительной патологии. У людей с болезнью Крона было выявлено до $2 \%$ новых случаев CRC через 10 лет, $8 \%$ - через 20 лет и $18 \%$ - через 30 лет [33].

С точки зрения этнических различий наиболее подверженными заболеванию являются чернокожие, а менее подверженными выходцы из Азии и островов Тихого океана. Это справедливо как в отношении заболеваемости $(43,2$ против 28,8 случаев на 100000 человек в год), так и смертности $(18,6$ против 9,9 случаев смерти на 100000 человек в год). В данном различии могут играть роль генетические факторы, например, у чернокожих было найдено несколько однонуклеотидных полиморфизмов, связанных с риском CRC $[18 ; 26]$.

Значительная роль принадлежит низкой информированности населения о факторах риска и их профилактике, а также о ранней диагностике CRC. Так, в 2018 г. в США лишь $65,2 \%$ взрослых в возрасте 50-75 лет были в 
курсе скрининга CRC (тремя годами ранее $47,4 \%$ ). Но среди индейского населения, латиноамериканцев и выходцев из Азии величина показателя находилась в пределах 55-57 \%, а среди лиц без медицинской страховки только $29,7 \%$ [8; 36].

\section{Участие микрофлоры в образовании рака толстой кишки}

Кишечная флора, эпителиальные клетки слизистой оболочки, пищевые пробиотические компоненты и малые молекулы - включая гормоны, ферменты, слизь и желчные соли - составляют сложную кишечную микроэкосистему, которая является устойчивой системой в физиологических условиях [32; 42].

В этом обзоре мы обобщаем известные данные о влиянии кишечной микробиоты на фенотип CRC, описываем факторы, которые способны повлиять на состав кишечной микробиоты и показываем стратегии, которые могут быть применены в экспериментальных проектах, с учетом влияния микробиоты на развитие CRC. Тщательное планирование на основе вышесказанного, будет способствовать продвижению исследований, направленных на профилактику и лечение CRC [20].

Механизм углеводного обмена играет важную роль в развитии CRC. Во-первых, кислород участвует в углеводных метаболичес- ких путях, а $\mathrm{CO}_{2}$ и $\mathrm{H}_{2} \mathrm{O}$ основами метаболитами углеводного обмена, и они связаны с развитием CRC [22; 37; 42]. Во-вторых, АТФ вырабатывается во время углеводного обмена и снабжает все живые клетки энергией. Фосфорибоза, образующаяся при метаболизме пентозофосфата, необходима для синтеза ДНК и РНК, а это в свою очередь является основным компонентом для быстрой пролиферации бактериальных и раковых. В-третьих, НАДФН является промежуточным метаболитом, который участвует в фосфорилировании белков и генов, и может быть вовлечен в микробную изменчивость и эпигенетическую регуляцию CRC. B-четвертых, митохондрии являются ключевым местом для углеводного обмена, а митохондриальная дисфункция является одной из наиболее важных особенностей при CRC и дисбалансе кишечной флоры [32].

Высокое содержание жиров способствует развитию CRC, так как происходит увеличение секреции желчи и желчных кислот в толстой кишке, а некоторые клостридии могут ускорять превращение желчной кислоты во вторичные кислоты с канцерогенным действием (рис. 1) [30]. Аминокислотный обмен также играет роль в канцерогенезе. Многие токсичные вещества, такие как сера, нитраты, сероводород, аммиак и амины, образуются под влиянием аминокислотного обмена и могут привести к развитию CRC [9; 31].

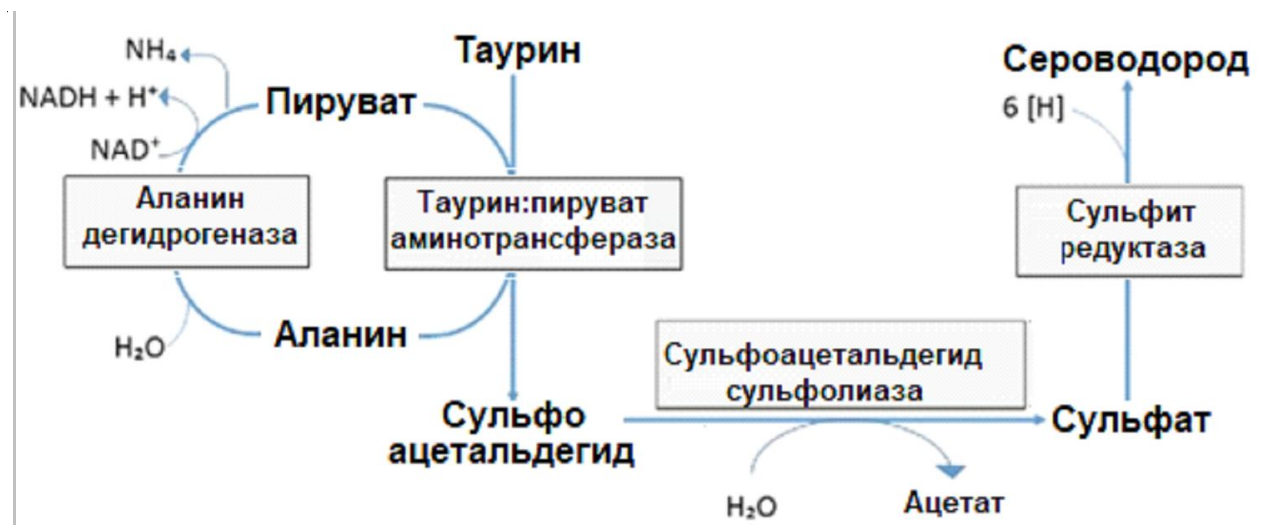

Рис. 1. Окисление таурина в Bilophila wadsworthia

Примечание. Процесс проходит в 3 ферментативных этапа. Вначале таурин трансанимируется с помощью фермента таурин:пируватаминотрансферазы с получением аланина и сульфоацетальдегида. Затем сульфоацетальдегид под действием сульфоацетальдегид-сульфолиазы с образованием ацетата и сульфата. На последнем этапе сульфат восстанавливается диссимиляционной сульфитредуктазой до сероводорода с использованием электронных доноров, таких как водород и формиат. Для завершения цикла аланин превращается обратно в пируват с помощью аланин-дегидрогеназы [30]. 
К настоящему времени, за более, чем 50 летний период изучения участия кишечной микрофлоры в развитии опухолей данной локализации, приведено достаточно большое число доказательств того, что микроорганизмы кишечника играют ключевую роль в канцерогенезе. Среди представителей микрофлоры по значимости в возникновении и прогрессировании CRC играют такие виды, как как Bacteroides, Escherichia, Fusobacterium и Porphyromonas [13-15; 40].

Кроме того, было обнаружено, что численность некоторых видов, таких как $F$. nucleatum и Solobacterium moorei, была увеличена на ранней и поздней стадии развития рака, а некоторых, таких как Atopobium parvulum и Actinomyces odontolyticus, только на ранней, что может быть потенциально использовано в качестве биомаркеров для ранних аденоматозных поражений [12]. Некоторые специфические бактерии, такие как Bacteroides fragilis, Streptococcus bovis, Escherichia coli, Enterococcus faecalis и Streptococcus gallolyticus, очень тесно связаны c CRC $[14 ; 15 ; 17]$. Недавние исследования на людях выявили новые штаммы бактерий, участвующие в CRC канцерогенезе, к ним относятся бактерии таких родов, как Parvimonas, Peptostreptococcus, Porphyromonas и Prevotella, а также Fusobacterium nucleatum [23; 24; 29; 41].

\section{Роль $\beta$-глюкуронидазы при раковых заболеваниях}

$\beta$-глюкуронидаза относится к семейству гликозидаз, стимулирующих расщепление сложных углеводов. Глюкуронидаза человека, находящаяся в лизосоме, катализирует остаток d-глюкуроновой кислоты из не восстанавливающего конца гликозаминогликанов, например гепарансульфата. В кишечнике она превращает конъюгированный билирубин в не конъюгированную форму для реабсорбции. в-глюкуронидаза человека соответствует ферменту $\beta$-галактозидазы Escherichia coli. На данном основании, а также с учетом того, что гликозидазы выполняют гидролиз, вызванный кислотными остатками, была предложена гипотеза, которая гласит о том, что остатки глутаминовой кислоты Glu540 и Glu451 являются кислотными и нуклеофильными остатками, а остаток тирозина Tyr504 участвует в катализе.
На основе анализа меченных gl-глюкуронидазой пептидов исследователи установили, что Glu540 является внутриядерным отходом, возникающим в ходе реакции нуклеофильного замещения SN2 с участием оксикарбениевого иона.

Человеческая $\beta$-D-глюкуронидаза (GUSB) состоит из 651 аминокислотного остатка (приблизительно 78 кДа), куда также входит сигнальный пептид длиной 22 аминокислотных остатка и четыре $\mathrm{N}$-связанных сайта гликозилирования. Четыре субъединицы образуют энзиматически-активный гомотетрамер. Структура мономера GUSB включает три структурных домена. Первый домен, который представляет собой бочкообразную структуру вместе с двумя вставками c b-шпилькой, обеспечивает механизм лизосомального нацеливания. Структура второго домена аналогична константному домену иммуноглобулина. Третий домен представляет собой мотив бочкового домена $\mathrm{a} / \mathrm{b}$ или TIM и обладает активным сайтом фермента, характерным ферментам гликозилгидролазы. Активный сайт мономера располагается на границе раздела олигомера и, следовательно, тетрамерный комплекс содержит четыре активных центра [25].

Глюкуронирование является основным путем детоксикации в печени млекопитающих, где происходит конъюгация гидрофобных ксенобиотиков и эндобиотиков с глюкуроновой кислотой, что приводит к увеличению их растворимости. Попавший в кишечник глюкуронид подвергается воздействию бактериальной $\beta$-глюкуронидазы, которая удаляет глюкуроновую кислоту, высвобождая исходные молекулы, что приводит к увеличению активных токсинов в кишечнике и увеличению времени жизни этих веществ в кровотоке (см. рис. 2) [2; 27; 28; 39].

Следовательно, активность GUSB влияет на физиологическую активность и токсичность различных лекарств и ксенобиотиков [7]. Кроме того, бактериальная активность GUSB в слепой кишке задерживает элиминацию эндокриноразрушающего агента, бисфенола А.

Кроме отрицательного воздействия, GUSB необходим для рециркуляции важных эндогенных молекул. Например, из глицирризина, диглюкуронидного конъюгата глицирре- 
тиновой кислоты можно получить глицирретиновую кислоту и моноглюкуронид глицирретиновой кислоты, чья биологическая активность выше, чем у соответствующих глюкуронидов [1]. Также известно, что эффективность церамид-глюкуронида против рака толстой кишки была связанна с активность GUSR, так как она продуцирует биоактивные церамиды (рис. 3) [6].

В кишечной микрофлоре GUS представляет собой лизосомальную экзогликозидазу, участвующую в деградации гликозаминогликанов клеточных мембран и внеклеточного матрикса нормальных и раковых тканей слизистой толстой кишки. Ее активность обычно увеличивается при различных катаболических состояниях. При легком окислительном стрессе некоторые лизосомы разрушаются и выделяют в цитозоль гидролитические ферменты, что сопровождается апоптозом и дальнейшим выделением гидролитических ферментов из клеток [38].

Сывороточная активность GUS у человека определяется поступлением собственно- го фермента из тканей и деятельностью кишечных бактерий (Escherichia coli, Peptostreptococcus, Bacteroides и Clostridia) (рис. 3) [38]. Оценка активности лизосомальных гидролаз в сыворотке и моче может быть полезна в диагностике колоректальной аденокарциномы $[3 ; 16 ; 21]$. Например, у пациентов, потребляющих большое количество мяса, активность $\beta$-глюкуронидазы выше, чем у людей на вегетарианской диете [34].

\section{Методы выделения, очистки и определение активности $\beta$-глюкуронидазы}

Tamura и др. проводили оценку активности фермента со следующими модификациями: кишечные суспензии $(1: 100)$ в фосфатном буфере с $\mathrm{pH} 7$ и добавляли 0,05 мл 0,12 M п-нитрофенил-в-D-глюкуронида и инкубировали при $37{ }^{\circ} \mathrm{C}$ в течение 1 часа, реакцию останавливали с помощью 0,4 М глицин$\mathrm{NaOH}$ буфера (pH 10,5) и далее центрифуги-
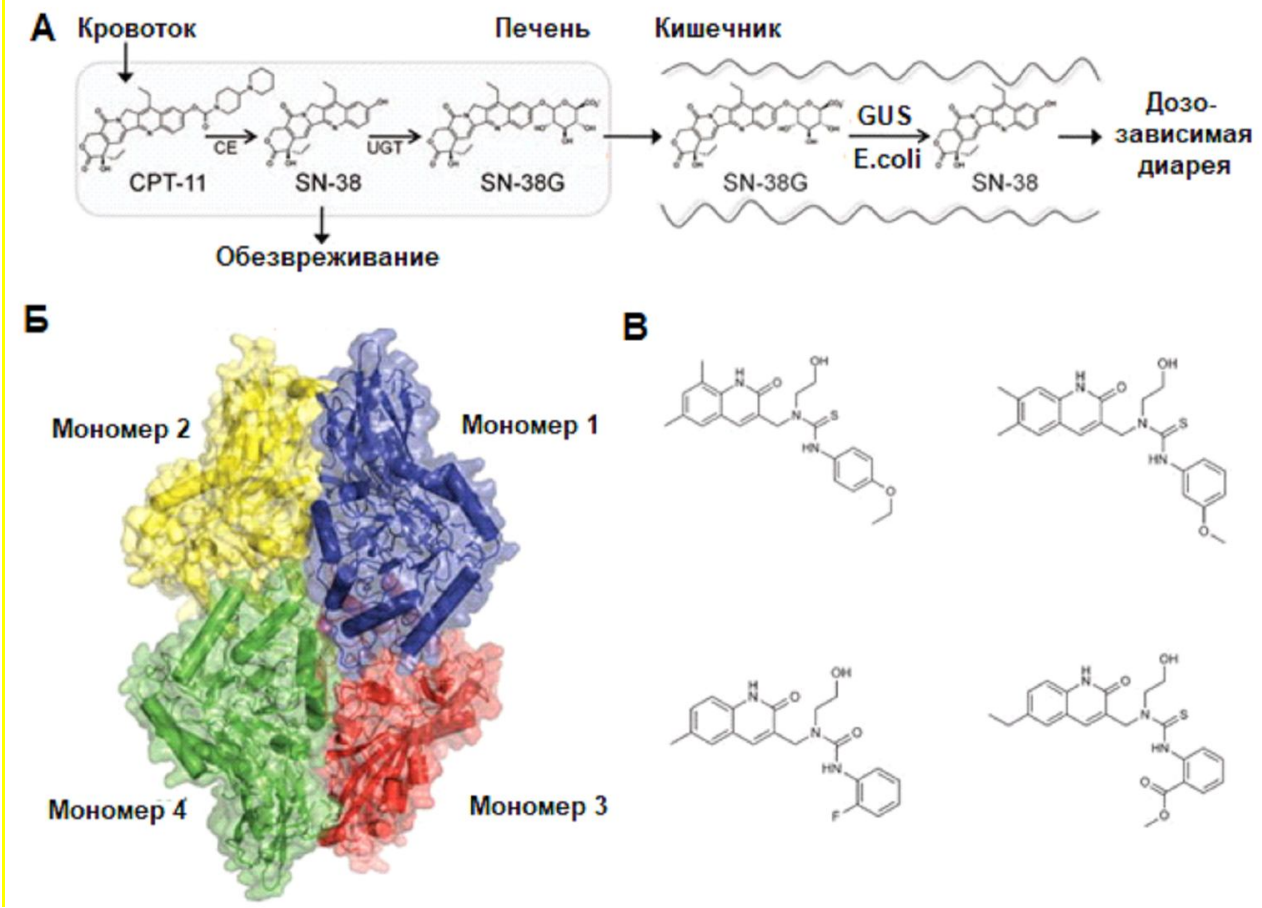

B

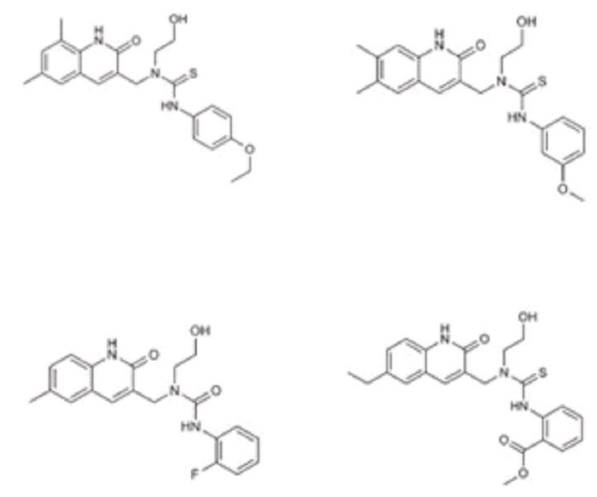

Рис. 2. Метаболизм СРТ-11 и $\beta$-глюкуронидаза E. coli

А. Внутривенно введенный СРТ-11 активируется карбоксилэстеразами (CE) до SN-38. В печени СН-38 инактивируется путем глюкуронирования, и SN-38G отправляется в кишечник, где бактерии вновь удаляют глюкуронид, а свободный активный SN-38 в просвете кишечника вызывает дозозависимую диарею.

В. Кристаллическая структура тетрамера b-глюкуронидазы Е. coli с разрешением 2,5 А С. Четыре селективных бактериальных ингибитора b-глюкуронидазы, идентифицированных с помощью высокопроизводительного скрининга [2] 
ровали при $4500 \mathrm{~g}$ в течение 5 минут. Абсорбцию надосадочной жидкости оценивали спектрометрически при длине волны 400 нм. Калибровочный график был построен с использованием п-нитрофенола. Анализ концентрации белка в гомогенатах, полученных путем разрушения клеток аналогичного количества кишечного содержимого, проводился с использованием метода Брэдфорда. Активность $\beta$-глюкуронидазы регистрировали в виде микромолей п-нитрофенола, высвобождаемых через 60 минут на грамм белка кишечного содержимого [4].

Для анализа активности $\beta$-глюкуронидазы также применялись хромогенные субстраты такие как индоксил- $\beta$-D-глюкуронид (IBDG). Изменения ферментативной активно- сти проводили спектрофотометрическим методом с использованием Microplate Reader ELx 808 (Biowhittaker, Walkersville, MA, USA) при $44,5^{\circ} \mathrm{C}$ и 450 нм. Показания оптической плотности снимали сразу после добавления субстрата, а именно в момент времени 0 и при увеличении времени инкубации $(2,3,5,7$, 21 часа), чтобы оценить влияние периода инкубации на экспрессию фермента [5].

\section{Применение $\beta$-глюкуронидазы в лечении колоректального рака}

Условно-патогенные бактерии локализованные в желудочно-кишечной тракте часто возбудителями некоторых заболеваний, но фармацевтические компании разрабатывают

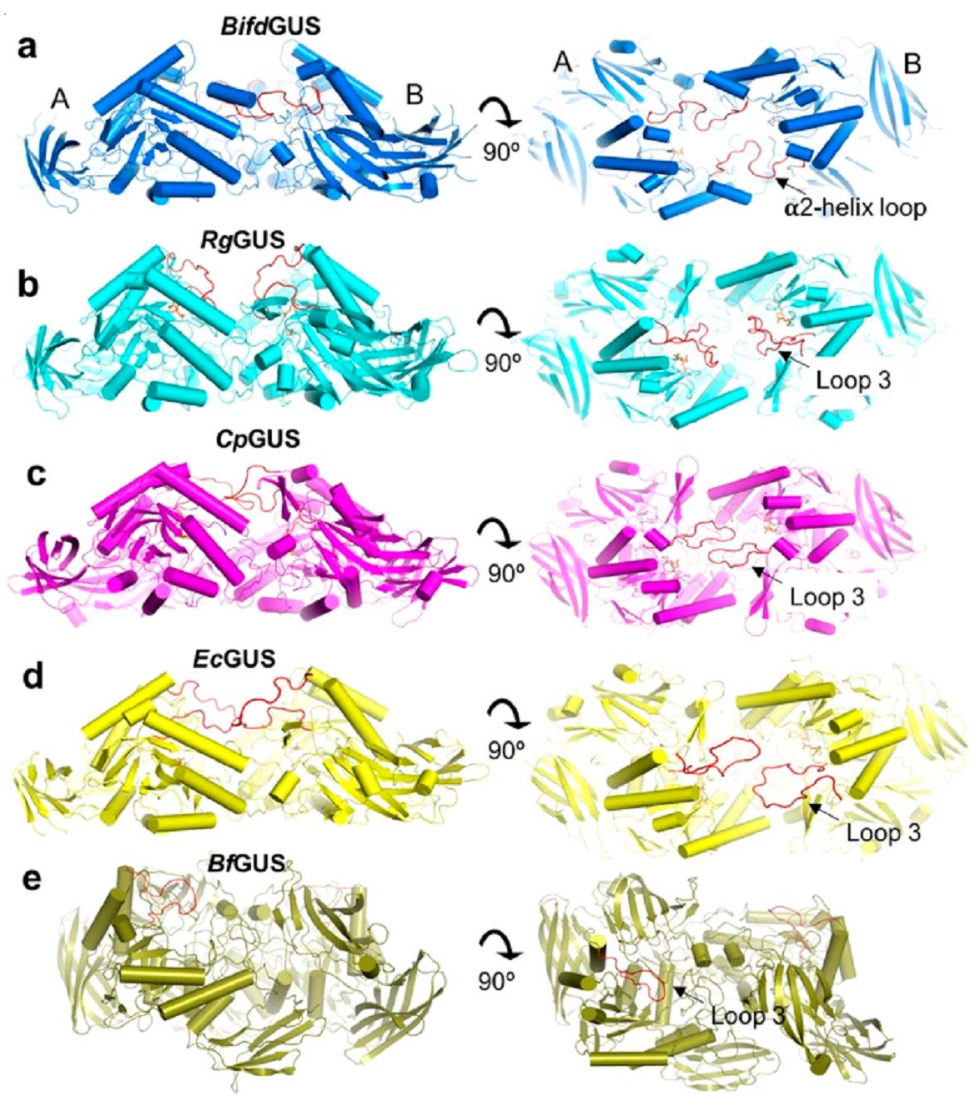

Рис. 3. Сравнение димерных структур GUSs у основных представителей бактерий

Примечание. Вид с верху и сбоку (a) BifdGUS - Bifidobacterium dentium; (b) RgGUS - Ruminococcus gnavus; (c) CpGUS - Clostridium perfringens; (d) EcGUS - Escherichia coli and (e) BfGUS - Bacteroides fragilis. Красным цветом выделены петли, расположенные на периферии ТIM-ствола (loop 3), либо в области скопления альфа-спиралей (a2-helix loop). Каждая петля альфа спирали у BifdGUS (a) достигает участка соседней субъединицы. Петли (loop 3) у $C p$ GUS (c) и $E c$ GUS (d) простирается от своей до соседней субъединицы. И в тоже время у RgGUS (b) не контактирует с соседней субъединицей. Димерная структура BfGUS (e) ориентирована иначе, чем у других, поскольку активный участок двух мономеров направлен в противоположные стороны [6]. 
новые подходы по их использованию для лечения некоторых видов рака, что может стать «революцией» в медицинской сфере. Недавние результаты показали, что пациенты с высоким уровнем условно-патогенных кишечных бактерий более чувствительны к современной иммунотерапии вследствие чего биотехнологические компании начали конкурировать в разработке лекарств для борьбы с раком на основе использования микроорганизмов. Одним из таких примеров является PD-1, способствующий борьбе с раком, стимулируя клетки иммунной системы организма.

Бактерии, которые были модифицированы для селективной противоопухолевой активации проактивных противораковых агентов, были исследованы как перспективный подход для достижения более селективной терапии CRC [11; 19]. В данном исследовании была рассмотрена возможность усиления действия противоопухолевого препарата СРТ-11 путем систематического введения E.coli, которые были сконструированы для экспрессии $\beta$-глюкуронидазы, которая может превращать SN$38 \mathrm{G}$ в $\mathrm{SN}-38$ и увеличивать противораковую активность от SN-38G до культивируемых раковых клеток примерно в 100 раз.

Существует два основных преимущества использования E. coli в качестве средства доставки и активации пролекарства. Во-первых, кишечная палочка способна избирательно колонизировать солидные опухоли, обеспечивая высокий коэффициент колонизации опухоли/нормальной ткани примерно в 10000 раз. Во-вторых, в отличие от липосом, антител или вирусов с недостаточной репликацией, бактерии могут размножаться в опухолях. Длительная колонизация опухолей может позволить многократное введение пролекарства после одной инъекции E.coli. Также было выявлены и недостатки, а именно снижение эффективности терапия с использованием b-глюкуронидазы: 1) медленное поглощение глюкуронидных соединений в E. coli может снижать скорость гидролиза пролекарства; 2) преимущественное накопление E. coli в некротических областях опухолей может препятствовать эффективному контакту систематически назначаемых препаратов c b-глюкуронидазой. Данное исследование показывает, что как клеточное, так и пространственное распределение b-глюкуронидазы и, возможно, других терапевтических ферментов может быть важным барьером для эффективной терапии рака основе использования бактерий.

\section{Заключение}

Колоректальный рак является третьим по частоте заболеваемости в мире и поэтому изучение данной темы является актуальной проблемой. Данное заболевание может развиваться из-за нарушений кишечной микрофлоры, в том числе и из-за повышения активности $\beta$-глюкуронидазы. Поэтому использование ее в качестве биомаркера для обнаружения и предотвращения развития CRC на ранних этапах является важным шагом в борьбе с этой болезнью. Помимо этого, были проведены исследования по применению бактериальной GUSB E. coli для борьбы с раком, как элемент комплексной химиотерапии, который усиливал действие противоопухолевого препарата СРТ-11, переводя его в активную форму. Дальнейшее изучение $\beta$-глюкуронидазы и ее роль в развитии колоректального рака может поспособствовать снижению уровня заболеваемости и смертности по данному заболеванию.

\section{СПИСОК ЛИТЕРАТУРЫ}

1. A Metagenomic $\beta$-Glucuronidase Uncovers a Core Adaptive Function of the Human Intestinal Microbiome/ K. Gloux [et al.] // Proc. Natl. Acad. Sci. USA. - 2010. - Vol. 108, suppl. 1. - P. 4539-4546. DOI: https://doi.org/10.1073/pnas.1000066107.

2. Alleviating Cancer Drug Toxicity by Inhibiting a Bacterial Enzyme / B. D. Wallace [et al.] // Science. 2010. - Vol. 330, iss. 6005. - P. 831-835. DOI: https:// doi.org/10.1126/science. 1191175 .

3. Altobelli, E. Role of Urinary Biomarkers in the Diagnosis of Adenoma and Colorectal Cancer: a Systematic Review and Meta-Analysis / E. Altobelli, P. M. Angeletti, G. Latella // J. Cancer. 2016. - Vol. 7, № 14. - P. 1984-2004. DOI: https://doi.org/10.7150/ jca. 16244.

4. $\beta$-Glucuronidase Activity Determination as an Indirect Estimate of Escherichia Coli: Development of a Miniaturized Assay and Its Application to Seawater Samples / G. Caruso [et al.] // J. Clin. Microbiol. Biochem. Technol. - 2017. - Vol. 3, № 3. - P. 46-50. DOI: https://doi.org/10.17352/jcmbt.000027.

5. $\beta$-Glucuronidase Activity in Germ-Free, Monoassociated and Conventional Mice/ M. E. Cardona, 
E. Norin, T. Midtvedt//Microb. Ecol. Health Dis. - 2009.Vol. 18, № 1.-P. 38-41. DOI: https://doi.org/10.1080/ 08910600600733264.

6. $\beta$-Glucuronidases of Opportunistic Bacteria are the Major Contributors to Xenobiotic-Induced toxicity in the Gut / P. Dashnyam, R. Mudududdla, T.J. Hsieh // Sci. Rep. -2018. - Vol. 8, № 1.-P. el6372. DOI: https:/ /doi.org/10.1038/s41598-018-34678-z.

7. Carmody, R. N. Host-Microbial Interactions in the Metabolism of Therapeutic and Diet-Derived Xenobiotics / R. N. Carmody, P. J. Turnbaugh // J. Clin. Invest. - 2014. - Vol. 124, № 10. - P. 4173-4181. DOI: https://doi.org/10.1172/JCI72335.

8. Colorectal Cancer Screening in the United States: Trends from 2008 to 2015 and Variation by Health Insurance Coverage / J. S. de Moor [et al.] // Prev. Med. 2018. - Vol. 112. - P. 199-206. DOI: https://doi.org/ 10.1016/j.ypmed.2018.05.001.

9. Contributions of the Interaction Between Dietary Protein and Gut Microbiota to Intestinal Health / N. Ma [et al.] // Curr. Protein Pept. Sci. - 2017. Vol. 18, № 8. -P. 795-808. DOI: https://doi.org/10.2174/ 1389203718666170216153505.

10. Familial Risk and Heritability of Colorectal Cancer in the Nordic Twin Study of Cancer / R. E. Graff [et al.] // Clin. Gastroenterol. Hepatol. - 2017. - Vol. 15, № 8. - P. 1256-1264. DOI: https://doi.org/10.1016/ j.cgh.2016.12.041.

11. Forbes, N. S. Engineering the Perfect (Bacterial) Cancer Therapy / N. S. Forbes // Nat. Rev. Cancer. - 2010. - Vol. 10. - P. 785-794. DOI: https:// doi.org/10.1038/nrc2934.

12. Fusobacterium is Associated with Colorectal Adenomas / A. N. McCoy [et al.] // PLoS One. -2013. - Vol. 8, № 1. - P. e53653. DOI: https://doi.org/10.1371/ journal.pone.0053653.

13. Fusobacterium Nucleatum Infection is Prevalent in Human Colorectal Carcinoma / M. Castellarin [et al.] // Genome Res. - 2012. - Vol. 22, № 2. - P. 299-306. DOI: https://doi.org/10.1101/ gr.126516.111.

14. Gut Bacteria and Their Metabolites: Which One is the Defendant for Colorectal Cancer? / S. Tarashi [et al.] // Microorganisms. - 2019. - Vol. 7, № 11. - P. e561. DOI: https://doi.org/10.3390/ microorganisms7110561.

15. Gut Microbiome Development Along the Colorectal Adenoma-Carcinoma Sequence / Q. Feng [et al.] // Nat Commun. - 2015. - Vol. 11. - P. e6528. DOI: https://doi.org/10.1038/ncomms7528.

16. Häuselmann, I. Altered Tumor-Cell Glycosylation Promotes Metastasis / I. Häuselmann, L. Borsig // Front. Oncol. -2014. - Vol. 4. - P. e28. DOI: https://doi.org/10.3389/fonc.2014.00028.

17. Human Gut Microbiome and Risk for Colorectal Cancer / J. Ahn [et al.] // J. Natl. Cancer
Inst. - 2013. - Vol. 105, № 24. - P. 1907-1911. DOI: https://doi.org/10.1093/jnci/djt300.

18. Identification of Novel Mutations by Exome Sequencing in African American Colorectal Cancer Patients/H. Ashktorab [etal.] //Cancer.-2015. -Vol. 121, № 1.-P. 34-42. DOI: https://doi.org/10.1002/cncr.28922.

19. Lehouritis, P. Bacterial-Directed Enzyme Prodrug Therapy / P. Lehouritis, C. Springer, M. Tangney// J. Control Release. - 2013. - Vol. 170.P. 120-131. DOI: https://doi.org/10.1016/ j.jconrel.2013.05.005.

20. Leystra, A. A. Gut Microbiota Influences Experimental Outcomes in Mouse Models of Colorectal Cancer/A. A. Leystra, M. L. Clapper// Genes (Basel). 2019. - Vol. 10, № 11. - P. e900. DOI: https://doi.org/ 10.3390/genes 10110900 .

21. Lysosomal Exoglycosidases and Cathepsin D in Colon Adenocarcinoma / N. Waszkiewicz, B. Zalewska-Szajda [et al.] // Pol. Arch. Med. Wewn.2012. - Vol. 122, № 11. - P. 551-556.

22. Major Anaerobic Bacteria Responsible for the Production of Carcinogenic Acetaldehyde from Ethanol in the Colon and Rectum / A. Tsuruya [et al.] // Alcohol Alcohol. - 2016. - Vol. 51, № 4. - P. 395-401. DOI: https://doi.org/10.1093/alcalc/agv135.

23. Meta-Analysis of Fecal Metagenomes Reveals Global Microbial Signatures That are Specific for Colorectal Cancer / J. Wirbel [et al.] // Nat. Med. 2019. - Vol. 25, № 4. - P. 679-689. DOI: https://doi.org/ 10.1038/s41591-019-0406-6.

24. Metagenomic and Metabolomic Analyses Reveal Distinct Stage-Specific Phenotypes of the Gut Microbiota in Colorectal Cancer / S. Yachida [et al.] // Nat. Med. - 2019. - Vol. 25, № 6. - P. 968-976. DOI: https://doi.org/10.1038/s41591-019-0458-7.

25. Human $\beta$-Glucuronidase: Structure, Function, and Application in Enzyme Replacement Therapy/ H. Naz [et al.] // Rejuvenation Res. - 2013.Vol. 16, № 5. - P. 352-363. DOI: https://doi.org/10.1089/ rej.2013.1407.

26. Novel Colon Cancer Susceptibility Variants Identified from a Genome-Wide Association Study in African Americans / H. Wang [et al.] // Int. J. Cancer. 2017. - Vol. 140, № 12. - P. 2728-2733. DOI: https:// doi.org/10.1002/ijc.30687.

27. Pellock, S. J. Glucuronides in the Gut: SugarDriven Symbioses Between Microbe and Host / S. J. Pellock, M. R. Redinbo // J. Biol. Chem. -2017. Vol. 292, № 21. - P. 8569-8576. DOI: https://doi.org/ 10.1074/jbc.R116.767434.

28. Pharmacological Targeting of Bacterial $\beta$ Glucuronidase Alleciates Nonsteroidal AntiInflammatory Drug-Induced Enteropathy in Mice / A. LoGuidice [et al.] // J. Pharmacol. Exp. Ther. -2012.Vol. 341, № 2. - P. 447-454. DOI: https://doi.org/ 10.1124/jpet.111.191122. 
29. Potential of Fecal Microbiota for Early-Stage Detection of Colorectal Cancer / G. Zeller [et al.] // Mol. Syst. Biol. - 2014. - Vol. 10. - P. e766. DOI: https:/ /doi.org/10.15252/msb.20145645.

30. Ridlon, J. M. Taurocholic Acid Metabolism by Gut Microbes and Colon Cancer / J. M. Ridlon, P. G. Wolf, H. R. Gaskins // Gut Microbes. - 2016. Vol. 7, № 3. - P. 201-215. DOI: https://doi.org/10.1080/ 19490976.2016 .1150414$.

31. Role of Intestinal Flora in Colorectal Cancer from the Metabolite Perspective: a Systematic Review / S. Han [et al.] // Cancer Manag. Res. - 2018. - Vol. 10. P. 199-206. DOI: https://doi.org/10.2147/ CMAR.S153482.

32. Saint-Georges-Chaumet, Y. MicrobiotaMitochondria Inter-Talk: Consequence for Microbiotahost Interaction / Y. Saint-Georges-Chaumet, M. Edeas // Pathog. Dis. - 2016. - Vol. 74, № 1. - P. ftv096. DOI: https://doi.org/10.1093/femspd/ftv096.

33. Serum Beta-Glucuronidase in Colon Cancer Patients Dependent on Alcohol and Nicotine: Preliminary Report / N. Waszkiewicz [et al.] // Prog. Health Sci. - 2012. - Vol. 2, № 2. - P. 64-69. DOI: https:/ /doi.org/10.5604/17322693.1064081.

34. Serum $\beta$-Glucuronidase as a Potential Colon Cancer Marker: a Preliminary Study / N.Waszkiewicz [et al.] // Postępy Hig. Med. Dośw. - 2015. - Vol. 69. P. 436-439. DOI: https://doi.org/10.5604/ 17322693.1148704 .

35. Shuwen, H. Can Mitochondria DNA Provide a Novel Biomarker for Evaluating the Risk and Prognosis of Colorectal Cancer? / H. Shuwen, Y. Xi, P. Yuefen // Dis. Markers. - 2017. - P. e5189803. DOI: https://doi.org/10.1155/2017/5189803.

36. Siegel, R. L. Cancer Statistics, $2019 /$ R. L. Siegel, K. D. Miller, A. Jemal // C. A. Cancer J. Clin. -2019. - Vol. 69. - P. 7-34. DOI: https://doi.org/ 10.3322/caac. 21551.

37. Superoxide-Hydrogen Peroxide Imbalance Interferes with Colorectal Cancer Cells Viability, Proliferation and Oxaliplatin Response / V. F. Azzolin [et al.] // Toxicol. In Vitro. - 2016. - Vol. 32. - P. 8-15. DOI: https://doi.org/10.1016/j.tiv.2015.12.001.

38. The Biological Role of D-Glucaric Acid and its Derivatives: Potential Use in Medicine / R. Żółtaszek [et al.] // Postępy Hig. Med. Dośw. - 2008. - Vol. 62.P. 451-462.

39. The Microbial Pharmacists Within Us: a Metagenomic View of Xenobiotic Metabolism / P. Spanogiannopoulos [et al.] // Nat. Rev. Microbiol. 2016. - Vol. 14, № 5. - P. 273-287. DOI: https://doi.org/ 10.1038/nrmicro.2016.17.

40. The Role of Fusobacterium nucleatum in Colorectal Cancer: from Carcinogenesis to Clinical Management / C. H. Sun [et al.] // Chronic Dis. Transl.
Med. - 2019. - Vol. 5, № 3. - P. 178-187. DOI: https:// doi.org/10.1016/j.cdtm.2019.09.001.

41. Thomas, A. M. Metagenomic Analysis of Colorectal Cancer Datasets Identifies Cross-Cohort Microbial Diagnostic Signatures and a Link with Choline Degradation / A. M. Thomas, P. Manghi, F. Asnicar//Nat. Med. -2019. - Vol. 25, № 4. - P. 667-678. DOI: https://doi.org/10.1038/s41591-019-0405-7.

42. Vinke, P. C. The Role of Supplemental Complex Dietary Carbohydrates and Gut Microbiota in Promoting Cardiometabolic and Immunological Health in Obesity: Lessons from Healthy Non-Obese Individuals / P. C. Vinke, S. ElAidy, G. van Dijk// Front Nutr. - 2017. - Vol. 4. - P. e34. DOI: https://doi.org/ $10.3389 /$ fnut.2017.00034.

\section{REFERENCES}

1. Gloux K., Berteau O., El Oumami H., et al. A Metagenomic $\beta$-Glucuronidase Uncovers a Core Adaptive Function of the Human Intestinal Microbiome. Proc. Natl. Acad. Sci. USA, 2010, vol. 108, suppl. 1, pp. 4539-4546. DOI: https://doi.org/ 10.1073/pnas. 1000066107.

2. Wallace B.D., Wang H., Lane K.T., et al. Alleviating Cancer Drug Toxicity by Inhibiting a Bacterial Enzyme. Science, 2010, vol. 330, iss. 6005, pp. 831-835. DOI: https://doi.org/10.1126/science.1191175.

3. Altobelli E., Angeletti P.M., Latella G. Role of Urinary Biomarkers in the Diagnosis of Adenoma and Colorectal Cancer: a Systematic Review and MetaAnalysis. J. Cancer, 2016, vol. 7, no. 14, pp. 19842004. DOI: https://doi.org/10.7150/jca.16244.

4. Caruso G., Caruso R., Monticelli L.S., et al. $\beta$ Glucuronidase Activity Determination as an Indirect Estimate of Escherichia Coli: Development of a Miniaturized Assay and Its Application to Seawater Samples. J. Clin. Microbiol. Biochem. Technol., 2017, vol. 3, no. 3, pp. 46-50. DOI: https://doi.org/10.17352/ jcmbt.000027.

5. Cardona M.E., Norin E., Midtvedt T. $\beta$ Glucuronidase Activity in Germ-Free, Monoassociated and Conventional Mice. Microb. Ecol. Health Dis., 2009, vol. 18, no. 1, pp. 38-41. DOI: https://doi.org/10.1080/ 08910600600733264.

6. Dashnyam P., Mudududdla R., Hsieh T.J. $\beta$ Glucuronidases of Opportunistic Bacteria are the Major Contributors to Xenobiotic-Induced toxicity in the Gut. Sci. Rep., 2018, vol. 8, no. 1, pp. e16372. DOI: https:// doi.org/10.1038/s41598-018-34678-z.

7. Carmody R.N., Turnbaugh P.J. Host-Microbial Interactions in the Metabolism of Therapeutic and DietDerived Xenobiotics. J. Clin. Invest., 2014, vol. 124, no. 10, pp. 4173-4181. DOI: https://doi.org/10.1172/JCI72335. 
8. de Moor J.S., Cohen R.A., Shapiro J.A., et al. Colorectal Cancer Screening in the United States: Trends from 2008 to 2015 and Variation by Health Insurance Coverage. Prev. Med., 2018, vol. 112, pp. 199-206. DOI: https://doi.org/10.1016/j.ypmed.2018.05.001.

9. Ma N., Tian Y., Wu Y., Ma X. Contributions of the Interaction Between Dietary Protein and Gut Microbiota to Intestinal Health. Curr. Protein Pept. Sci., 2017, vol.18, no. 8, pp. 795-808. DOI: https:// doi.org/10.2174/1389203718666170216153505.

10. Graff R.E., Möller S., Passarelli M.N., et al. Familial Risk and Heritability of Colorectal Cancer in the Nordic Twin Study of Cancer. Clin. Gastroenterol. Hepatol., 2017, vol. 15, no. 8, pp. 1256-1264. DOI: https://doi.org/10.1016/j.cgh.2016.12.041.

11. Forbes, N.S. Engineering the Perfect (Bacterial) Cancer Therapy. Nat. Rev. Cancer., 2010, vol. 10, pp. 785-794. DOI: https://doi.org/10.1038/nrc2934.

12. McCoy A.N., Araújo-Pérez F., Azcárate-Peril A., et al. Fusobacterium is Associated with Colorectal Adenomas. PLoS One, 2013. vol. 8, no 1. pp. e53653. DOI: https://doi.org/10.1371/journal.pone.0053653.

13. Castellarin M., Warren R.L., Freeman J.D., et al. Fusobacterium Nucleatum Infection is Prevalent in Human Colorectal Carcinoma. Genome Res., 2012, vol. 22, no. 2 , pp. 299-306. DOI: https://doi.org/10.1101/gr.126516.111.

14. Tarashi S., Siadat S.D., Ahmadi Badi S., et al. Gut Bacteria and Their Metabolites: Which One is the Defendant for Colorectal Cancer? Microorganisms, 2019, vol. 7, no. 11, pp. e561. DOI: https://doi.org/ 10.3390/microorganisms7110561.

15. Feng Q., Liang S., Jia H., et al. Gut Microbiome Development Along the Colorectal AdenomaCarcinoma Sequence. Nat Commun, 2015. vol. 11, pp. e6528. DOI: https://doi.org/10.1038/ncomms 7528 .

16. Häuselmann, I., Borsig L. Altered Tumor-Cell Glycosylation Promotes Metastasis. Front. Oncol., 2014. vol. 4, pp. e28. DOI: https://doi.org/10.3389/ fonc.2014.00028.

17. Ahn J., Sinha R., Pei Z., et al. Human Gut Microbiome and Risk for Colorectal Cancer. J. Natl. Cancer Inst., 2013, vol. 105, no. 24, pp. 1907-1911. DOI: https://doi.org/10.1093/jnci/djt300.

18. Ashktorab H., Daremipouran M., Devaney J., et al. Identification of Novel Mutations by Exome Sequencing in African American Colorectal Cancer Patients. Cancer, 2015. vol. 121, no. 1, pp. 34-42. DOI: https://doi.org/10.1002/cncr.28922.

19. Lehouritis P., Springer C., Tangney M. Bacterial-Directed Enzyme Prodrug Therapy. J. Control Release, 2013, vol. 170, pp. 120-131. DOI: https://doi.org/10.1016/j.jconrel.2013.05.005.

20. Leystra A.A., Clapper M.L. Gut Microbiota Influences Experimental Outcomes in Mouse Models of Colorectal Cancer. Genes (Basel), 2019, vol. 10, no. 11, pp. e900. DOI: https://doi.org/10.3390/genes10110900.
21. Waszkiewicz N., Zalewska-Szajda B., Szajda S.D., et al. Lysosomal Exoglycosidases and Cathepsin $\mathrm{D}$ in Colon Adenocarcinoma. Pol. Arch. Med. Wewn., 2012, vol. 122, no. 11, pp. 551-556.

22. Tsuruya A., Kuwahara A., Saito Y., et al. Major Anaerobic Bacteria Responsible for the Production of Carcinogenic Acetaldehyde from Ethanol in the Colon and Rectum. Alcohol Alcohol, 2016, vol. 51, no. 4, pp. 395-401. DOI: https://doi.org/10.1093/alcalc/ agv135.

23. Wirbel J., Pyl P.T., Kartal E., et al. MetaAnalysis of Fecal Metagenomes Reveals Global Microbial Signatures That are Specific for Colorectal Cancer. Nat. Med, 2019, vol. 25, no. 4, pp. 679-689. DOI: https://doi.org/10.1038/s41591-019-0406-6.

24. Yachida S., Mizutani S., Shiroma H., et al. Metagenomic and Metabolomic Analyses Reveal Distinct Stage-Specific Phenotypes of the Gut Microbiota in Colorectal Cancer. Nat. Med, 2019. vol. 25, no. 6, pp. 968-976. DOI: https://doi.org/10.1038/s41591019-0458-7.

25. Naz H., Islam A., Waheed A., et al. Human $\beta$ Glucuronidase: Structure, Function, and Application in Enzyme Replacement Therapy. Rejuvenation Res, 2013. vol. 16, no. 5, pp. 352-363. DOI: https://doi.org/ 10.1089/rej.2013.1407.

26. Wang H., Schmit S.L., Haiman C.A., et al. Novel Colon Cancer Susceptibility Variants Identified from a Genome-Wide Association Study in African Americans. Int. J. Cancer, 2017. vol. 140, no. 12. pp. 2728-2733. DOI: https://doi.org/10.1002/ijc.30687.

27. Pellock, S.J., Redinbo, M.R. Glucuronides in the Gut: Sugar-Driven Symbioses Between Microbe and Host. J. Biol. Chem., 2017, vol. 292, no. 21, pp. 85698576. DOI: https://doi.org/10.1074/jbc.R116.767434.

28. LoGuidice A., Wallace B.D., Bendel L., et al. Pharmacological Targeting of Bacterial b-Glucuronidase Alleciates Nonsteroidal Anti-Inflammatory DrugInduced Enteropathy in Mice. J. Pharmacol. Exp. Ther., 2012. vol. 341, no. 2. pp. 447-454. DOI: https://doi.org/ 10.1124/jpet.111.191122.

29. Zeller G., Tap J., Voigt A.Y., et al. Potential of Fecal Microbiota for Early-Stage Detection of Colorectal Cancer. Mol. Syst. Biol., 2014. vol. 10, pp. e766. DOI: https://doi.org/10.15252/msb.20145645.

30. Ridlon, J.M. Wolf, P.G., Gaskins, H.R. Taurocholic Acid Metabolism by Gut Microbes and Colon Cancer. Gut Microbes, 2016, vol. 7, no. 3, pp. 201215. DOI: https://doi.org/10.1080/19490976.2016.1150414.

31. Han, S., Jianlan, G., Qing, Z., et al. Role of Intestinal Flora in Colorectal Cancer from the Metabolite Perspective: a Systematic Review. Cancer Manag. Res., 2018, vol. 10, pp. 199-206. DOI: https:// doi.org/10.2147/CMAR.S153482.

32. Saint-Georges-Chaumet, Y., Edeas, M. Microbiota-Mitochondria Inter-Talk: Consequence for 
Microbiota-Host Interaction. Pathog. Dis., 2016. vol. 74, no. 1, pp. ftv096. DOI: https://doi.org/10.1093/ femspd/ftv096.

33. Waszkiewicz N., Zalewska-Szajda B., Repka B., et al. Serum Beta-Glucuronidase in Colon Cancer Patients Dependent on Alcohol and Nicotine: Preliminary Report. Prog. Health Sci., 2012, vol. 2, no. 2, pp. 64-69. DOI: https://doi.org/10.5604/17322693.1064081.

34. Waszkiewicz N., Szajda S.D., KonarzewskaDuchnowska E., et al. Serum $\beta$-Glucuronidase as a Potential Colon Cancer Marker: a Preliminary Study. Postępy Hig. Med. Dośw., 2015, vol. 69, pp. 436-439. DOI: https://doi.org/10.5604/17322693.1148704.

35. Shuwen H., Xi Y., Yuefen P. Can Mitochondria DNA Provide a Novel Biomarker for Evaluating the Risk and Prognosis of Colorectal Cancer? Dis. Markers, 2017, pp. e5189803. DOI: https://doi.org/10.1155/2017/5189803.

36. Siegel R.L., Miller K.D., Jemal A. Cancer Statistics, 2019. C. A. Cancer J. Clin., 2019, vol. 69, pp. 7-34. DOI: https://doi.org/10.3322/caac.21551.

37. Azzolin V.F., Cadoná F.C., Machado A.K., et al. Superoxide-Hydrogen Peroxide Imbalance Interferes with Colorectal Cancer Cells Viability, Proliferation and Oxaliplatin Response. Toxicol. in Vitro, 2016, vol. 32, pp. 8-15. DOI: https://doi.org/ 10.1016/j.tiv.2015.12.001.
38. Żółtaszek R., Hanausek M., Kiliańska Z.M., Walaszek Z. The Biological Role of D-Glucaric Acid and its Derivatives: Potential Use in Medicine. Postęy Hig. Med. Dośw, 2008, vol. 62, pp. 451-462.

39. Spanogiannopoulos P., Bess E.N., Carmody R.N., Turnbaugh P.J. The Microbial Pharmacists Within Us: a Metagenomic View of Xenobiotic Metabolism. Nat. Rev. Microbiol., 2016, vol. 14, no. 5, pp. 273-287. DOI: https://doi.org/10.1038/nrmicro.2016.17.

40. Sun C.H., Li B.B., Wang B., et al. The Role of Fusobacterium nucleatum in Colorectal Cancer: from Carcinogenesis to Clinical Management. Chronic Dis. Transl. Med., 2019, vol. 5, no. 3, pp. 178-187. DOI: https://doi.org/10.1016/j.cdtm.2019.09.001.

41. Thomas A.M., Manghi P., Asnicar F., et al. Metagenomic Analysis of Colorectal Cancer Datasets Identifies Cross-Cohort Microbial Diagnostic Signatures and a Link with Choline Degradation. Nat. Med., 2019, vol. 25, no. 4, pp. 667-678. DOI: https:// doi.org/10.1038/s41591-019-0405-7.

42. Vinke P.C. El Aidy S., van Dijk G. The Role of Supplemental Complex Dietary Carbohydrates and Gut Microbiota in Promoting Cardiometabolic and Immunological Health in Obesity: Lessons from Healthy Non-Obese Individuals. Front Nutr., 2017, vol. 4, e34. DOI: https://doi.org/10.3389/fnut.2017.00034.

\section{Information About the Authors}

Ahmed H. Al-Hemiri, Student, Department of Biology, Volgograd State University, Prosp. Universitetsky, 100, 400062 Volgograd, Russian Federation, ahmed.h.mneahil@gmail.com.

Moaed O. Aigazally, PhD (Biochemistry), College of Medicine, University of Al-Ameed, Najaf Highway Front of Pole, 1238, P.O.B. no. 198 Karbala, Iraq, moaedalgazally@yahoo.com.

Valery V. Novochadov, Doctor of Sciences (Medicine), Professor, Director of the Institute of Natural Sciences, Volgograd State University, Prosp. Universitetsky, 100, 400062 Volgograd, Russian Federation, novochadov.valeriy@volsu.ru.

Anastasia A. Korchagina,Student, Department of Bioengineering and Bioinformatics, Volgograd State University, Prosp. Universitetsky, 100, 400062 Volgograd, Russian Federation, nastya.korchagina09@gmail.com.

\section{Информация об авторах}

Ахмед Хамид Хумаири, студент кафедры биологии, Волгоградский государственный университет, просп. Университетский, 100, 400062 г. Волгоград, Российская Федерация, ahmed.h.mneahil@gmail.com.

Мояд Омран Аль-Газали, $\mathrm{PhD}$ по биохимии, профессор университета Аль-Амид, преподаватель в медицинском колледже, шоссе Наджаф Фронт полюса 1238, почтовый ящик 198 г. Карбала, Ирак, moaedalgazally@yahoo.com.

Валерий Валерьевич Новочадов, доктор медицинских наук, профессор, директор института естественных наук, Волгоградскоий государственный университет, просп. Университетский, 100, 400062 г. Волгоград, Российская Федерация, novochadov.valeriy@volsu.ru.

Анастасия Александровна Корчагина, студент кафедры биоинженерии и биоинформатики, Волгоградский государственный университет, просп. Университетский, 100, 400062 г. Волгоград, Российская Федерация, nastya.korchagina09@gmail.com. 